AVALIAÇÃO FÍSICO-QUÍMICA DE ÓLEO RESIDUAL DE CASTANHA-DOBRASIL (Bertholletia excelsa H.B.K.) E SUA CONVERSÃO EM BIODIESEL

\title{
Alcides Loureiro Santos $^{1}$, Nadma Farias Kunrath ${ }^{1}$, Israel Silva de Souza ${ }^{1}$, Carlos
} Eduardo Garção de Carvalho

${ }^{1}$ Pesquisador(a) da Divisão de Tecnologia de Energia de Fontes Renováveis da Fundação de Tecnologia do Estado do Acre (alcidesloureiroquimico@gmail.com) Rio Branco-Brasil

${ }^{2}$ Professor Doutor do Centro de Ciências Biológicas e da Natureza da Universidade Federal do Acre

Recebido em: 08/09/2015 - Aprovado em: 14/11/2015 - Publicado em: 01/12/2015 DOI: http://dx.doi.org/10.18677/Enciclopedia_Biosfera_2015_064

\begin{abstract}
RESUMO
A castanha-do-Brasil (Bertholletia excelsa H.B.K.) é uma das principais espécies oleaginosas amazônicas. Suas amêndoas são utilizadas essencialmente na alimentação humana. Contudo, dependendo do grau de degradação, elas podem ser consideradas impróprias para o consumo. Entretanto, é possível aproveitar o óleo, da castanha de baixa qualidade para a produção de biodiesel. Este trabalho tem como objetivo avaliar características físico-químicas do óleo de castanha-do-Brasil, obtido através da prensagem mecânica de amêndoas de baixa qualidade, e do biodiesel produzido através da transesterificação deste óleo. $O$ índice de acidez do óleo extraído ultrapassou o valor de $4,0 \mathrm{mgKOH} / \mathrm{g}$, limite estabelecido pela Agência Nacional de Vigilância Sanitária (ANVISA), para óleos e gorduras vegetais comestíveis. Foram realizadas quatro bateladas de transesterificação, sendo variadas a razão molar álcool/óleo (6/1 e 9/1) e a concentração de catalisador (1,0 e $1,5 \%$ ). O rendimento das bateladas foram superiores a $80 \%$, mesmo sem a realização do pré-tratamento da matéria-prima. Os resultados da maioria das análises físico-químicas do biodiesel apresentaram valores dentro da legislação estabelecida pela Agência Nacional do Petróleo, Gás Natural e Biocombustíveis (ANP), sugerindo a qualidade do biocombustível produzido.
\end{abstract}

PALAVRAS-CHAVE: análises físico-químicas, biodiesel, castanha-do-Brasil.

\section{PHYSICAL AND CHEMICAL EVALUATION OF CHESTNUT-BRAZIL-OIL (Bertholletia excelsa HBK) RESIDUAL AND CONVERSION IN YOUR BIODIESEL}

\begin{abstract}
Brazil nut (Bertholletia excelsa H.B.K.) is a major Amazonian oil varieties. Its almonds are mainly used in food. However, depending on the degree of degradation, it can be considered unsuitable for consumption. However, it is possible to use of the nut oil, even low quality for the production of biodiesel. This work aimed to evaluate physical and chemical characteristics of the Brazil nut oil, obtained by mechanical pressing of
\end{abstract}


low-quality almonds, and of the biodiesel produced by transesterification of the oil. The oil extracted from the acid value exceeded the value of $4.0 \mathrm{mg} \mathrm{KOH} / \mathrm{g}$, limit set by the National Health Surveillance Agency (ANVISA) for edible oils and vegetable fats. Four batches of transesterification were conducted, varying the molar ratio alcohol / oil (6/1 and 9/1) and catalyst concentration (1.0 and 1.5\%). The batch yields were more than $80 \%$, even without performing pre-treatment of the raw material. The results of most of the physical and chemical analysis of biodiesel showed values within the law established by the National Agency of Petroleum, Natural Gas and Biofuels (ANP), suggesting the quality of the produced biofuel.

KEYWORDS: chestnut-Brazil, biodiesel, physical-chemical analysis

\section{INTRODUÇÃO}

Nos últimos anos, pesquisas e investimentos têm sido realizados em busca do desenvolvimento e fortalecimentos de fontes alternativas de energia. Mesmo assim, é crescente a demanda mundial por combustíveis de origem fóssil, principalmente o petróleo, o gás natural e o carvão mineral. Tal situação expõe que, mesmo reconhecendo que fontes não renováveis causam sérios problemas ambientais, econômicos e até de saúde, a sociedade atual ainda é muito dependente destas fontes energéticas (SANTOS et al., 2014).

Considerando o ciclo do carbono, nota-se que a queima de combustíveis fósseis não é sustentável, devido às reservas fósseis que são finitas, como também à capacidade limitada de absorção de carbono do planeta (GONÇALVES, 2013). De acordo com dados da Agência Nacional do Petróleo, Gás Natural e Biocombustíveis (ANP), no Brasil, também é crescente o consumo de combustíveis derivados do petróleo desde o início do século XXI, conforme o Gráfico 1. Neste aspecto, observa-se que o óleo diesel é o combustível de maior consumo no país, superando, no ano de 2013, em 17 bilhões de litros o consumo da gasolina (OLIVEIRA, 2014).

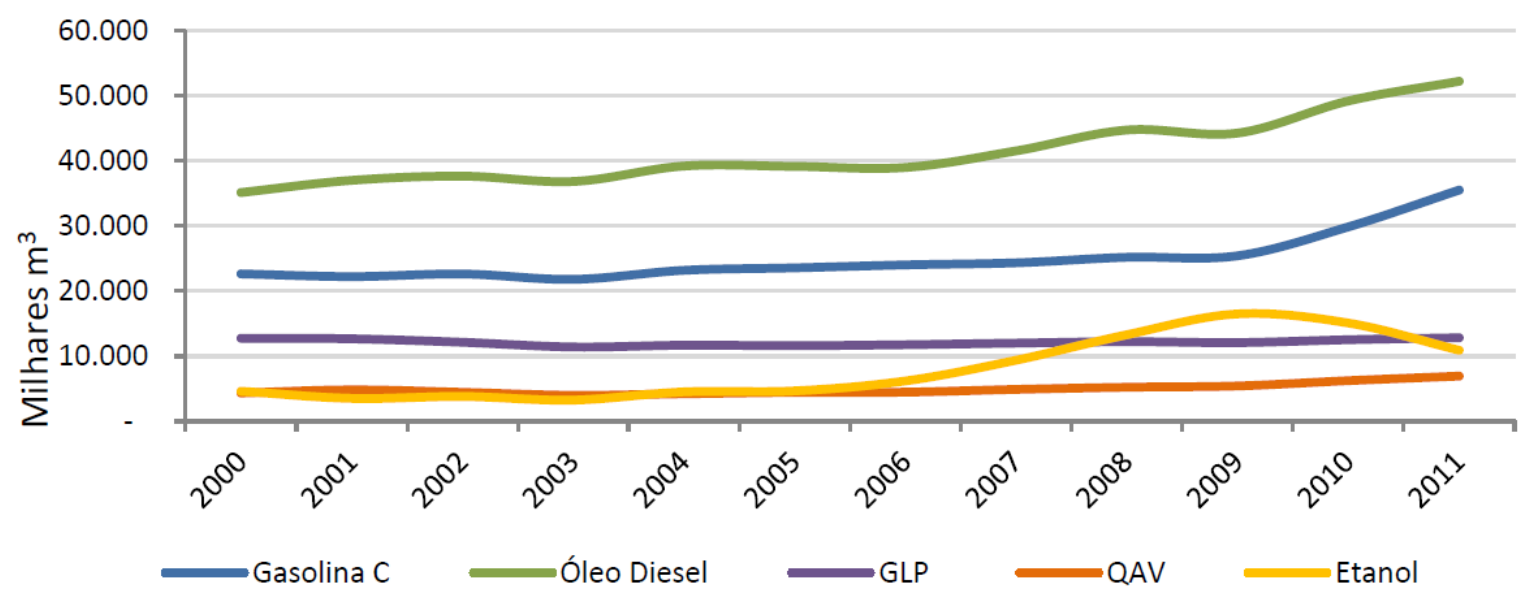

GRÁFICO 1. Consumo de combustíveis no Brasil. FONTE: BRASIL, (2013a).

O diesel derivado do petróleo (petrodiesel), além de ser proveniente de fonte fóssil, sua queima libera diversos poluentes atmosféricos, incluindo compostos de enxofre (GRANGEIRO, 2009). Uma das possíveis alternativas para a redução do consumo de diesel é através da utilização de óleos vegetais e as gorduras animais para a produção de biodiesel (CHAVES, 2008). 
Os óleos vegetais podem ser obtidos de espécies oleaginosas de cultivo (soja e girassol, por exemplo) ou através do extrativismo de espécies nativas. No Brasil, a gordura animal de maior produção é o sebo bovino. Estes materiais são constituídos basicamente por triacilglicerídeos (três cadeias carbônicas longas derivadas de ácidos graxos ligados na forma de ésteres a uma molécula de glicerol). Além disso, existem proporções menores de ácidos graxos livres (AGL) e de outros constituintes químicos (SOUZA et al., 2009).

Derivado dos óleos ou gorduras, o biodiesel é considerado um combustível renovável, biodegradável e de baixa toxidade. A combustão é mais limpa se comparado ao petrodiesel, emitindo baixas quantidades de compostos sulfurados, aromáticos, monóxidos de carbono e de material particulado. $\mathrm{O}$ biodiesel pode ser utilizado como substituto total ou parcial de diesel fóssil em motores de combustão interna que operam no ciclo diesel (JUBILUT, 2010).

De acordo com a ANP, a utilização do biodiesel como fonte de energia alternativa traz uma redução em média de $48 \%$ de monóxido de carbono (CO), $47 \%$ de material particulado e $67 \%$ de hidrocarbonetos. Porém, o biodiesel apresenta algumas desvantagens, tais como: emissão maior de óxidos de nitrogênio (NOx) menor poder calorífico e maior desgaste do motor, além de outras (MACHADO, 2013).

Tradicionalmente, o biodiesel é produzido a partir do processo de transesterificação (Figura 1). Nesta reação, um óleo (ou gordura) reage com uma solução alcoólica na presença de um catalisador ácido ou básico, sendo este último o mais usado pela sua melhor eficiência. Como produtos dessa transformação, têmse a glicerina (glicerol) e uma mistura de ésteres de ácidos graxos, o biodiesel (SANTOS et al., 2014). Desta forma, ele é definido quimicamente como ésteres monoalquílicos provenientes de ácidos graxos de cadeia longa (MACHADO, 2013).<smiles>CCOC(COC(=O)[OH2+])CC(=O)O</smiles>

triglicerídeo

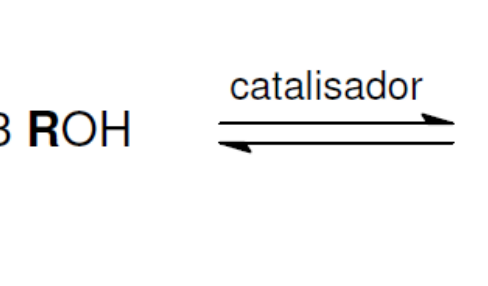

álcool
ROCOR'

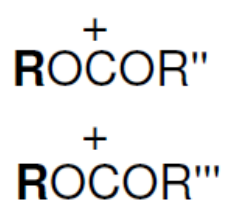

mistura de ésteres alquílicos<smiles>OCC(O)CO</smiles>

glicerol

FIGURA 1 - Reação de transesterificação.

Fonte: MACHADO (2013).

Na reação de transesterificação, o álcool deve ter cadeia curta, normalmente etanol ou metanol, sendo que os catalisadores mais usados são alcalinos, destacando-se os hidróxidos de potássio e de sódio (GONÇALVES, 2013). Apresentando viscosidade menor que dos óleos e gorduras, o biodiesel possui propriedades físicas e mecânicas que permitem a utilização em motores a diesel, sem a necessidade de modificações mecânicas (MACHADO, 2013).

No Brasil, as principais matérias-primas para a produção de biodiesel são o óleo de soja e o sebo bovino (Gráfico 2). Atualmente, $7 \%$ da composição do diesel comercializado nos postos de abastecimento do país é de biodiesel, mistura que recebe a denominação de $\mathrm{B} 7$. 


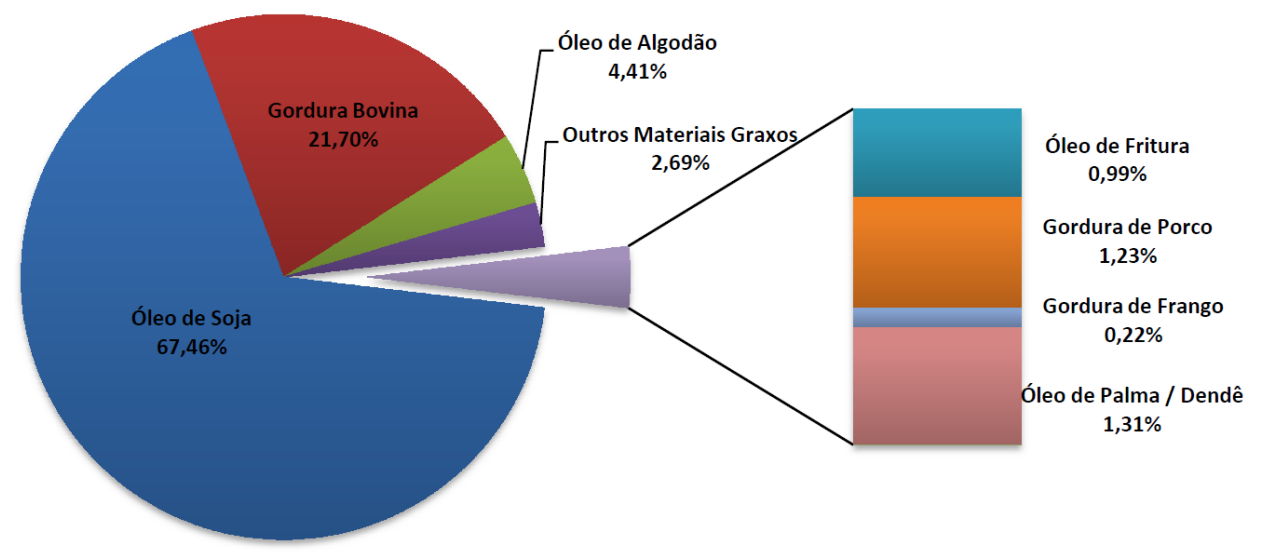

GRÁFICO 2. Perfil nacional de matérias-primas para a produção de biodiesel. FONTE: BRASIL, (2013b).

Geralmente, óleos vegetais extraídos de espécies amazônicas são destinados para a alimentação humana e para o mercado de cosméticos. Entretanto, a qualidade destes óleos poder estar comprometida se alguns parâmetros físicoquímicos não forem obedecidos. A Agência Nacional de Vigilância Sanitária (ANVISA), através de um regulamento técnico aprovado, legaliza a produção de óleos comestíveis. A Resolução de Diretoria Colegiada (RDC) de n‥270, de 22 de setembro de 2005, estabelece, por exemplo, que o índice de acidez (IA) de óleos vegetais comestíveis não deve ser superior a $4,0 \mathrm{mg} \mathrm{KOH} / \mathrm{g}$ de óleo (BRASIL, 2005).

Uma das espécies oleaginosas mais importantes da Amazônia é a castanhado-Brasil (Bertholletia excelsa H. B. K.). A atividade agroextrativista gera renda para as comunidades locais, além de que a cadeia produtiva contribui para a preservação da floresta dos países que exploram economicamente a castanha-do-Brasil, principalmente o Brasil, a Bolívia e o Peru (OLIVEIRA, 2011).

A amêndoa da castanha-do-Brasil é rica em óleo, sendo constituída de 60 a $70 \%$ de lipídios e de 15 a $20 \%$ de proteínas, além de outros constituintes (GONÇALVES, 2013). A amêndoa da castanha é conhecida por diversos nomes, destacando-se: amendoeira-da-América, castanha-do-Maranhão, castanha-do-Pará e castanha-do-Brasil (SOUZA, 2006). É um alimento muito apreciado nos estados da Região Amazônica devido ao sabor marcante, além de apresentar importantes qualidades nutricionais (FERREIRA et al., 2006).

Por meio do processo de prensagem mecânica das amêndoas, é possível se obter o óleo da castanha-do-Brasil. Este óleo pode ser utilizado na alimentação humana, na produção de cosméticos e de fármacos. Entretanto, caso as propriedades físico-químicas não apresentarem valores adequados à legislação vigente, a utilização para estes fins pode ser comprometida (FERREIRA et al., 2006).

Uma das possibilidades para o aproveitamento de óleos de castanha-doBrasil de baixa qualidade é sua utilização como matéria-prima para a produção de biodiesel. Tal aplicação, além de evitar o descarte inadequado desse material graxo no ambiente, possibilita a obtenção de um combustível renovável que pode ser usado para geração de energia elétrica ou no funcionamento de veículos a diesel.

Este trabalho teve como objetivo a produção de biodiesel transesterificado a partir de óleo de castanha-do-Brasil de baixa qualidade. Para isso, serão avaliadas 
algumas características físico-químicas do óleo de castanha-do-brasil, obtido através da prensagem mecânica e dos ésteres alquílicos produzidas.

\section{MATERIAL E MÉTODOS}

As amêndoas utilizadas são provenientes da Usina de Beneficiamento de Castanha Chico Mendes, situada no município de Xapuri (AC) e administrada pela Cooperativa Central de Comercialização Extrativista do Acre (COOPERACRE). Tais amêndoas eram de baixa qualidade e não atendiam as exigências da Usina para beneficiamento alimentício, conforme mostra a Figura 2. Elas foram prensadas mecanicamente na Divisão de Tecnologia de Energia de Fontes Renováveis (DITER), da Fundação de Tecnologia do Estado do Acre (FUNTAC). A prensa utilizada foi do tipo Expeller, modelo MP100 da marca ECIRTEC (Figura 3).

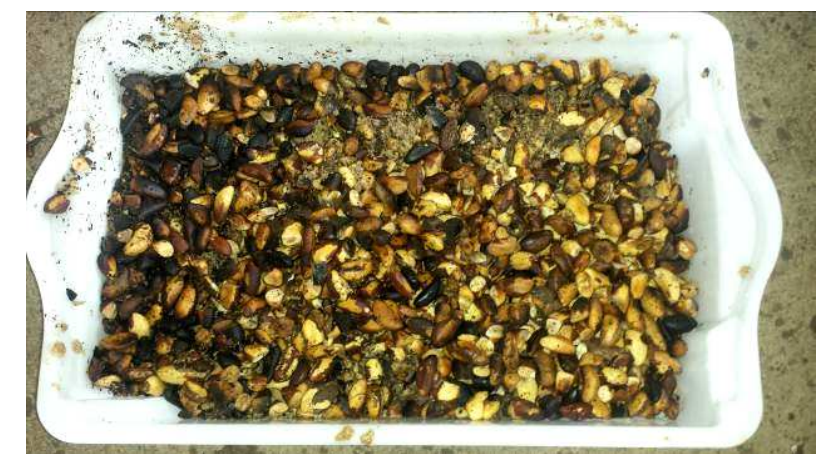

FIGURA 2 - Amêndoas de castanha-do-Brasil. Fonte: Autores

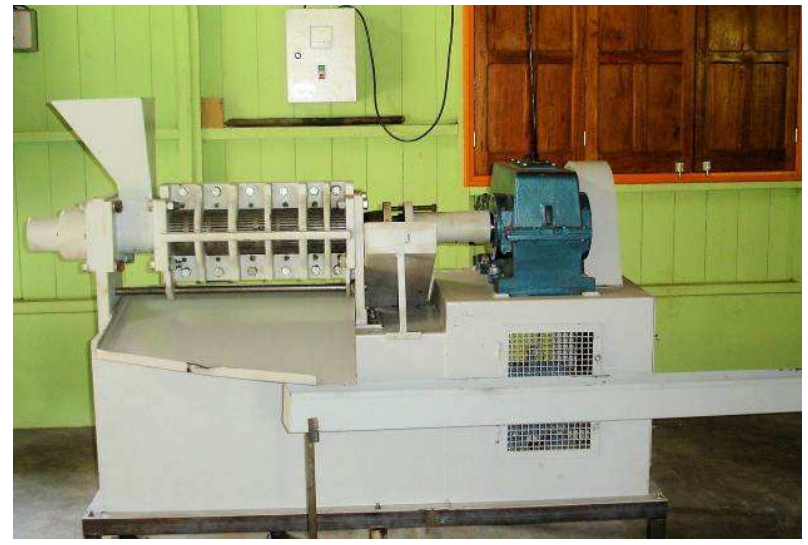

FIGURA 3 - Prensa mecânica MP100 - ERCITEC.

Fonte: Autores

Uma amostra de óleo bruto de castanha-do-Brasil foi separada, sendo submetida às seguintes análises: índice de acidez $(\mathrm{mgKOH} / \mathrm{g})$, massa específica a $20{ }^{\circ} \mathrm{C}(\mathrm{g} / \mathrm{mL})$, viscosidade cinemática a $40{ }^{\circ} \mathrm{C}\left(\mathrm{mm}^{2} / \mathrm{s}\right)$, índice de saponificação $(\mathrm{mgKOH} / \mathrm{g})$ e índice de voláteis (\%). As normas analíticas utilizadas foram baseadas nas seguintes referências: ABNT NBR 5849:1986, ABNT NBR 7148:2001 e normas analíticas do Instituto Adolfo Lutz (IAL, 2008). Todas as análises físico-químicas foram realizadas no Laboratório de Biocombustíveis da DITER. 
Para a reação de transesterificação foi adotada a rota metílica, utilizando razões molares álcool/óleo de 6/1 e 9/1. O hidróxido de potássio $(\mathrm{KOH})$ foi utilizado como catalisador da reação, sendo testadas as concentrações de 1 e $1,5 \%$ em relação a massa de óleo de castanha-do-Brasil. Após a reação, a mistura reacional foi decantada, para a remoção da fase da glicerina. A fase superior contendo os ésteres alquílicos foi lavada com água para a remoção de materiais residuais, como álcool e sabões. Foram realizadas hidrólises ácidas com solução ácido clorídrico $(\mathrm{HCl})$, a fim de acelerar as separações das fases biodiesel/água. Por fim, o biodiesel foi desumidificado para reduzir drasticamente a quantidade de água em sua composição.

Desta forma, foram realizadas quatro bateladas de transesterificação em laboratório. As amostras de óleo vegetal utilizadas não foram submetidas às etapas de pré-tratamento da matéria-prima. O fluxograma apresentado na Figura 4 resume as etapas realizadas para a produção de biodiesel de óleo de castanha-do-Brasil. A Tabela 1 apresenta os parâmetros usados nas reações.

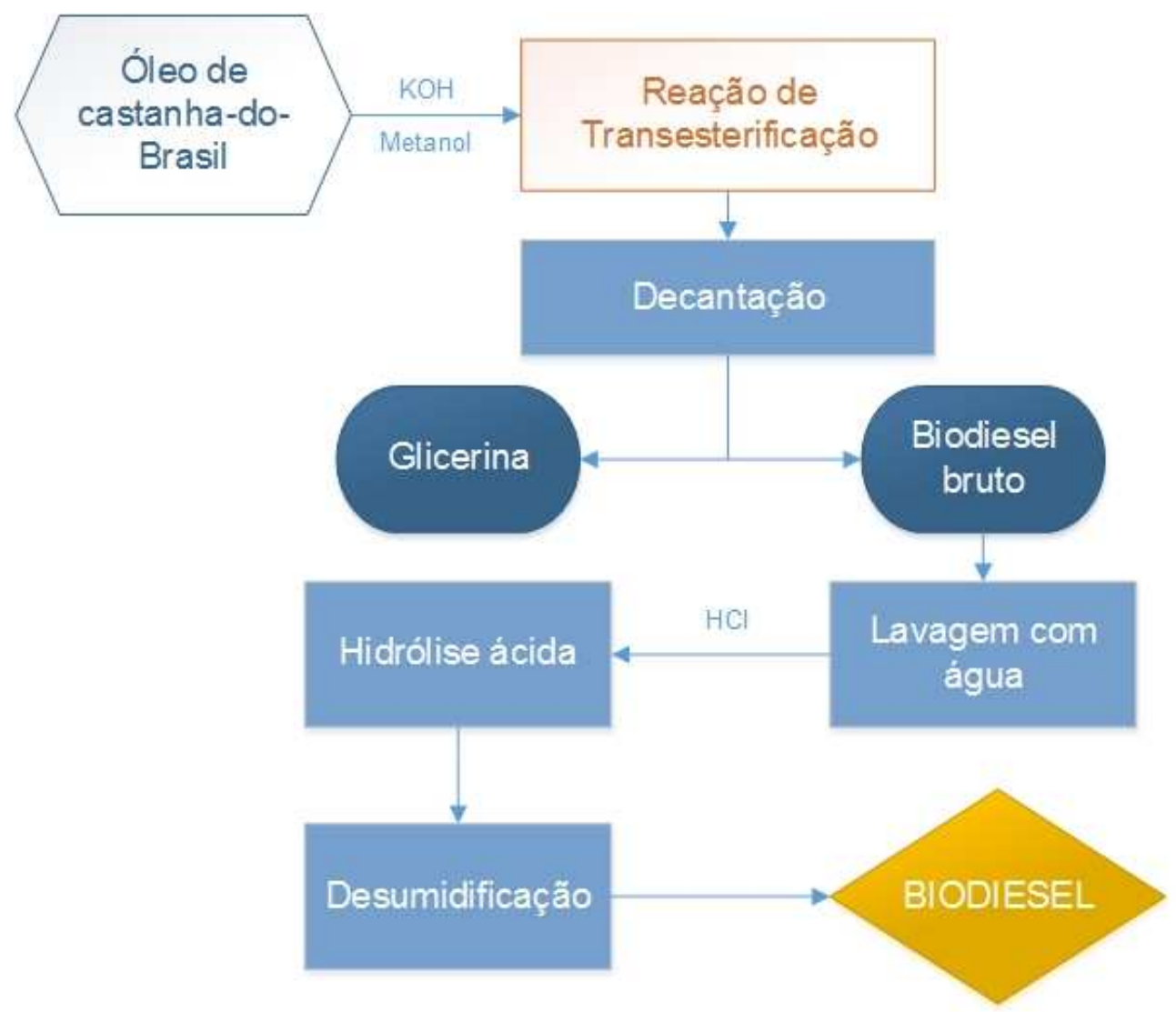

FIGURA 4 - Resumo das etapas da produção de biodiesel de óleo de castanha-do-Brasil.

Fonte: Autores 
TABELA 1 - Parâmetros usados nas reações de transesterificação

\begin{tabular}{|c|c|c|c|c|}
\hline $\begin{array}{c}\text { Razão molar } \\
\text { metanol/óleo + } \\
\% \mathrm{KOH}\end{array}$ & $\begin{array}{c}\text { 6:1 } \operatorname{com} 1 \% \\
\mathrm{KOH}\end{array}$ & $\begin{array}{c}\text { 6:1 } \operatorname{com} 1,5 \% \\
\mathrm{KOH}\end{array}$ & $\begin{array}{c}\text { 9:1 } \operatorname{com} 1 \% \\
\mathrm{KOH}\end{array}$ & $\underset{\mathrm{KOH}}{9: 1 \operatorname{com} 1,5 \%}$ \\
\hline Massa de óleo & $150 \mathrm{~g}$ & $150 \mathrm{~g}$ & $150 \mathrm{~g}$ & $150 \mathrm{~g}$ \\
\hline Massa de $\mathrm{KOH}$ & $1,93 \mathrm{~g}$ & $2,90 \mathrm{~g}$ & $1,93 \mathrm{~g}$ & $2,90 \mathrm{~g}$ \\
\hline $\begin{array}{l}\text { Massa de } \\
\text { Metanol }\end{array}$ & $32,88 \mathrm{~g}$ & $32,88 \mathrm{~g}$ & $49,32 \mathrm{~g}$ & $49,32 \mathrm{~g}$ \\
\hline $\begin{array}{l}\text { Temperatura de } \\
\text { reação }\end{array}$ & $60^{\circ} \mathrm{C}$ & $60^{\circ} \mathrm{C}$ & $60^{\circ} \mathrm{C}$ & $60^{\circ} \mathrm{C}$ \\
\hline $\begin{array}{l}\text { Tempo de } \\
\text { reação }\end{array}$ & $1 \mathrm{~h}$ & $1 \mathrm{~h}$ & $1 \mathrm{~h}$ & $1 \mathrm{~h}$ \\
\hline $\begin{array}{c}\text { Tempo de } \\
\text { decantação }\end{array}$ & $2 \mathrm{~h}$ & $2 \mathrm{~h}$ & $2 \mathrm{~h}$ & $2 \mathrm{~h}$ \\
\hline $\begin{array}{l}\text { Número de } \\
\text { lavagens }\end{array}$ & 3 & 3 & 3 & 3 \\
\hline $\begin{array}{l}\text { Condições da } \\
\text { desumidificação }\end{array}$ & 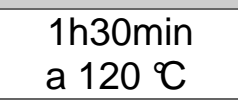 & 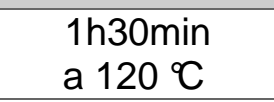 & 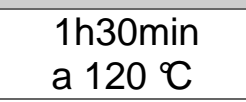 & 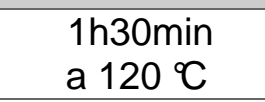 \\
\hline
\end{tabular}

Todas as amostras de biodiesel obtidas foram submetidas às seguintes análises físico-químicas: índice de acidez $(\mathrm{mgKOH} / \mathrm{g})$, massa específica a $20{ }^{\circ} \mathrm{C}$ $(\mathrm{g} / \mathrm{mL})$, viscosidade cinemática a $40 \mathrm{C}\left(\mathrm{mm}^{2} / \mathrm{s}\right)$, pon to de fulgor $\left({ }^{\circ} \mathrm{C}\right)$ e índice de voláteis (\%). Sendo adotadas as mesmas normas realizadas para as análises do óleo, excetuando o ponto de fulgor, que seguiu a ABNT NBR 14598.

\section{RESULTADOS E DISCUSSÃO}

Óleos e gorduras vegetais derivados de atividades extrativistas geralmente não são indicados para a produção industrial de biodiesel, principalmente devido aos elevados custos envolvidos na coleta, beneficiamento e extração destas matériasprimas. Contudo, levando em consideração materiais residuais de baixa qualidade, que não são mais aproveitados como alimentos e cosméticos, por exemplo, a produção de biocombustíveis pode ser uma alternativa interessante de destinação (SANTOS et al., 2014).

No caso deste trabalho, amêndoas de castanha-do-Brasil de qualidade indesejada foram submetidas ao processo de extração mecânica, visando a obtenção de óleo para a produção de biodiesel por transesterificação. Os valores obtidos das análises físico-químicas do óleo podem ser visualizados na Tabela 2.

TABELA 2 - Resultados das Análises físico-químicas do óleo de castanha-do-Brasil

\begin{tabular}{|lc|}
\hline \multicolumn{1}{c}{ ANÁLISES } & VALORES OBTIDOS \\
\hline Índice de acidez $(\mathbf{m g K O H} / \mathbf{g})$ & 4,18 \\
\hline Massa específica a $\mathbf{2 0} \mathbf{C}(\mathbf{g} / \mathbf{m L})$ & 0,9203 \\
\hline Viscosidade cinemática a $\mathbf{4 0} \mathbf{C}\left(\mathbf{m m}^{2} / \mathbf{s}\right)$ & 118,32 \\
\hline Índice de saponificação $(\mathbf{m g K O H} / \mathbf{g})$ & 195,99 \\
\hline Índice de voláteis $(\%)$ & 0,09 \\
\hline
\end{tabular}


FERREIRA et al. (2006), considerando a legislação da ANVISA para óleos e gorduras comestíveis, ressaltam que valores superiores a $4 \mathrm{mgKOH} / \mathrm{g}$ para o índice de acidez podem ser prejudiciais à saúde. O valor de $4,18 \mathrm{mgKOH} / \mathrm{g}$, encontrado para o óleo extraído das amêndoas de castanha-do-Brasil, mostra que sua qualidade para a segurança alimentar está comprometida. Os mesmos autores encontraram valores de 198,58 $\mathrm{mgKOH} / \mathrm{g}$ para o índice de saponificação e de 0,910 $\mathrm{g} / \mathrm{mL}$ para a massa específica, tais valores se aproximam dos obtidos neste trabalho.

Mesmo para a produção de biodiesel por meio do processo de transesterificação, valores elevados de índice de acidez podem prejudicar 0 rendimento da reação, além de elevar o número de etapas do processo. SILVA et al., (2013) sugerem que valores superiores a $3 \mathrm{mgKOH} / \mathrm{g}$ para óleos podem provocar reações químicas paralelas, como a saponificação, e por isso a matériaprima deve ser pré-tratada. Mesmo ultrapassando esse valor, as etapas de prétratamento não foram feitas para o óleo de castanha, a fim de garantir uma maior simplicidade do processo, evitando custos maiores em caso de produção em escala maior.

$\mathrm{Na}$ Tabela 3 estão apresentados os dados gerais obtidos para as quatro bateladas de transesterificação realizadas para o óleo de castanha-do-Brasil. A intenção de se realizar variações nas razões molares álcool/óleo e na concentração de catalisador foi de verificar os rendimentos reacionais e a qualidade do biodiesel obtido através de parâmetros diferentes. A massa inicial de óleo utilizada para cada batelada foi de $150 \mathrm{~g}$.

TABELA 3 - Resultados das bateladas de transesterificação de óleo de castanhado-Brasil em quatro diferentes condições reacionais

\begin{tabular}{ccccc}
\hline Informações & $\begin{array}{c}6: 1 \mathrm{com} \mathrm{1 \%} \\
\text { KOH }\end{array}$ & $\begin{array}{c}\mathbf{6 : 1} \text { com 1,5\% } \\
\text { KOH }\end{array}$ & $\begin{array}{c}9: 1 \text { com 1\% } \\
\text { KOH }\end{array}$ & $\begin{array}{c}9: 1 \text { com 1,5\% } \\
\text { KOH }\end{array}$ \\
\hline $\begin{array}{c}\text { Massa de } \\
\text { Biodiesel (antes } \\
\text { das lavagens) }\end{array}$ & $139,7536 \mathrm{~g}$ & $130,1250 \mathrm{~g}$ & $144,4588 \mathrm{~g}$ & $130,9812 \mathrm{~g}$ \\
\hline $\begin{array}{c}\text { Massa da fase } \\
\text { de glicerina }\end{array}$ & $29,8056 \mathrm{~g}$ & $42,4236 \mathrm{~g}$ & $34,7842 \mathrm{~g}$ & $46,0876 \mathrm{~g}$ \\
\hline $\begin{array}{c}\text { Massa de } \\
\text { biodiesel após a } \\
\text { desumidificação }\end{array}$ & $132,5143 \mathrm{~g}$ & $124,5073 \mathrm{~g}$ & $129,7509 \mathrm{~g}$ & $122,3563 \mathrm{~g}$ \\
\hline $\begin{array}{c}\text { Rendimento } \\
\text { final }\end{array}$ & $88,34 \%$ & $83,00 \%$ & $86,50 \%$ & $81,57 \%$ \\
\hline
\end{tabular}

Tratando-se de uma matéria-prima residual, os rendimentos reacionais obtidos podem ser considerados satisfatórios. É interessante notar que a batelada que obteve maior rendimento, $88,34 \%$, foi a $6: 1 \mathrm{com} 1 \% \mathrm{KOH}$. Ou seja, a reação que utilizou menor quantidade de álcool e de catalisador, foi a que produziu a maior quantidade de biodiesel. Isso era inesperado por que, na maioria das bateladas de transesterificação, quanto maior for a relação álcool/óleo maior é o rendimento da reação. Observou-se também que as duas bateladas que utilizaram 1,5\% de $\mathrm{KOH}$ como catalisador, apresentaram rendimentos inferiores se comparadas com aquelas que tiveram $1 \%$ de $\mathrm{KOH}$, nas mesmas razões molares metanol/óleo. 
A Figura 5 mostra as quatro bateladas em momentos diferentes. As duas da esquerda (razão 6/1) estavam em fases de lavagem e as duas da direita (razão 9/1), ainda durante a decantação da glicerina. Foi possível notar que, durante a lavagem, uma intensa massa branca na forma de emulsão foi formada em todas as bateladas. Conforme FERREIRA et al. (2006), o óleo da castanha-do-Brasil apresenta uma quantidade de $13 \%$ de ácidos graxos saturados. Estes ácidos, através de reações indesejáveis de saponificação, podem ter sido convertidos em sais de ácidos graxos responsáveis pela formação das emulsões.

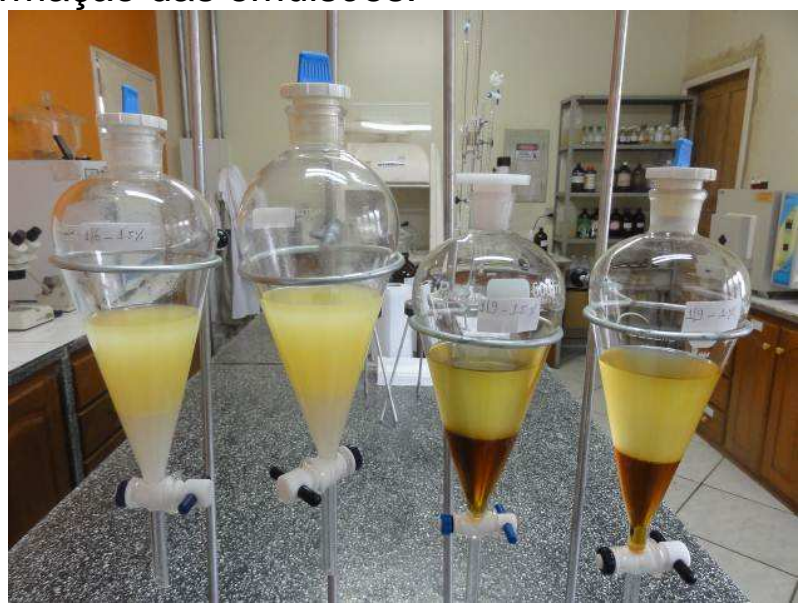

FIGURA 5 - Separação biodiesel/água após lavagem (duas da esquerda) e separação biodiesel/glicerina antes da lavagem (duas da direita).

Fonte: Autores .

Para "quebrar" as emulsões formadas, foi necessária a realização da etapa de hidrólise ácida. Esta consiste na adição de um ácido forte, no caso o clorídrico, à mistura emulsionada. Na Figura 6, é possível ver a eficiência da hidrólise através da quase ausência de emulsão e da coloração límpida da água de lavagem.

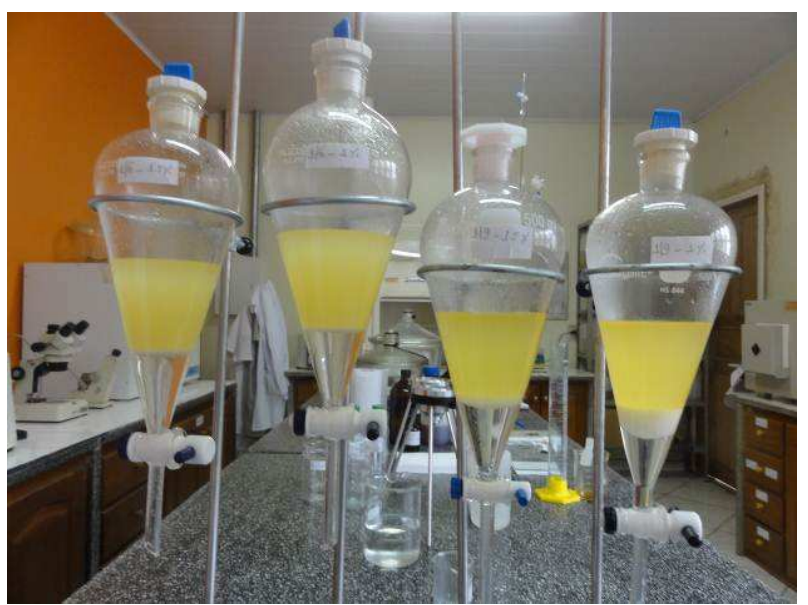

FIGURA 6 - Separação biodiesel/água após a hidrólise ácida.

Fonte: Autores 
Após o processo de desumidificação, as quatro amostras de biodiesel produzidas foram submetidas a cinco análises físico-químicas, conforme apesentado na Tabela 4. São apresentados também os valores estabelecidos pela RESOLUÇÃO ANP № 45, de 25 de agosto de 2014, referentes ao biodiesel B100.

TABELA 4 - Resultados das análises físico-químicas para as amostras de biodiesel produzidas

\begin{tabular}{|c|c|c|c|c|c|}
\hline Análises & $\begin{array}{l}6: 1 \mathrm{com} \\
1 \% \mathrm{KOH}\end{array}$ & $\begin{array}{c}\text { 6:1 com } \\
1,5 \% \mathrm{KOH}\end{array}$ & $\begin{array}{l}9: 1 \mathrm{com} \\
1 \% \mathrm{KOH}\end{array}$ & $\begin{array}{c}\text { 9:1 com } \\
1,5 \% \mathrm{KOH}\end{array}$ & B100 ANP \\
\hline $\begin{array}{l}\text { Índice de acidez } \\
(\mathrm{mgKOH} / \mathrm{g})\end{array}$ & 0,23 & 0,34 & 0,23 & 0,28 & $\begin{array}{l}\text { Máximo } \\
0,50\end{array}$ \\
\hline $\begin{array}{l}\text { Massa específica a } \\
20^{\circ} \mathrm{C}(\mathrm{g} / \mathrm{mL})\end{array}$ & 0,8832 & 0,8779 & 0,8821 & 0,8791 & $\begin{array}{c}0,850 \mathrm{a} \\
0,900\end{array}$ \\
\hline $\begin{array}{c}\text { Viscosidade } \\
\text { cinemática }\left(\mathrm{mm}^{2} / \mathrm{s}\right)\end{array}$ & 6,46 & 5,79 & 6,11 & 5,88 & 3,0 a 6,0 \\
\hline Ponto de fulgor $\left({ }^{\circ} \mathrm{C}\right)$ & 178 & 180 & 178 & 180 & Mínimo 100 \\
\hline Índice de voláteis (\%) & 0,15 & 0,10 & 0,24 & 0,22 & - \\
\hline
\end{tabular}

Sobre o índice de acidez, todas as amostras de biodiesel de óleo de castanha-do-Brasil ficaram dentro do limite da ANP. Segundo DIB (2010), valores baixos de índice de acidez sugerem a baixa concentração remanescente de ácidos graxos livres e, consequentemente, a qualidade do biodiesel. Além disso, todos os valores de massa específica estão dentro da faixa estabelecida pela agência e próximos entre si.

Os valores obtidos para a viscosidade cinemática de duas amostras de biodiesel produzidas com $1 \%$ de hidróxido de potássio ultrapassaram o limite superior de $6,0 \mathrm{~mm}^{2} / \mathrm{s}$. A menor quantidade de base pode ter permitido a presença de pequenas quantidades de óleo não transesterificado no biodiesel. Santos et al. (2014) também observaram viscosidade cinemática elevada para biodiesel produzido a partir de óleo residual de fritura. Contudo, a preparação de mistura Bx (diesel + biodiesel) pode readequar a viscosidade para os limites da ANP. É importante ressaltar que inicialmente o óleo apresentava o valor de $118,32 \mathrm{~mm} / \mathrm{s}$, mas, com a sua conversão em ésteres metílicos, houve uma redução drástica da viscosidade, contribuindo para sua utilização em motores a diesel (SILVA, 2008).

$O$ ponto de fulgor para as amostras de biodiesel produzidas atenderam à legislação da ANP. Isso é importante porque valores baixos de fulgor podem potencializar incêndios e explosões, devido à emissão de vapores inflamáveis (SILVA, 2008). Os índices de voláteis (água e outros materiais voláteis) determinados foram baixos, contudo a ANP não regulamente está análise, apenas considera o valor de teor de água máxima.

\section{CONCLUSÃO}

Os resultados das análises do óleo de castanha-do-Brasil indicaram o não atendimento da legislação da ANVISA para óleos e gorduras comestíveis. Desta forma, foi possível determinar a possibilidade de produção de biodiesel transesterificado, mesmo que o óleo apresente baixa qualidade. Os altos 
rendimentos reacionais e os resultados das análises físico-químicas das amostras de biodiesel indicam que, tecnicamente, a produção deste biocombustível pode ser uma alternativa de destinação de óleos vegetais de baixa qualidade. Alterações nos parâmetros da transesterificação podem aumentar o rendimento da reação.

\section{REFERÊNCIAS}

BRASIL. Ministério de Minas e Energia. Agência Nacional do Petróleo, Gás Natural e Biocombustíveis. ANP, (2013a). Evolução do mercado de combustíveis e derivados: 2000-2012. Disponível em: <www.anp.gov.br/?dw=64307>. Acesso em: 28 maio 2014.

BRASIL. Ministério de Minas e Energia. Agência Nacional do Petróleo, Gás Natural e Biocombustíveis. ANP, (2013b). Boletim Mensal do Biodiesel: Março de 2013. Disponível em: <http://www.biomercado.com.br/imagens/publicacao/arquivo47.pdf.>. Acesso em: 28 maio 2014.

BRASIL. Resolução RDC/ANVISA/MS no 270, de 22 setembro de 2005. Regulamento técnico para óleos vegetais, gorduras vegetais e creme vegetal. Diário Oficial [da] República Federativa do Brasil. Brasília, DF, 23 set. 2005. Seção 1.

CHAVES, A. T. C. A. Otimização do processo de produção de biodiesel etílico do óleo de girassol (Hellianthus annus) aplicando um delineamento composto central rotacional (DCCR). 2008. 90 f. Dissertação (Mestrado em Química) Universidade Federal da Paraíba, João Pessoa, 2008.

DIB, F. H. Produção de biodiesel a partir de óleo residual reciclado e realização de testes comparativos com outros tipos de biodiesel e proporções de mistura em um moto-gerador. 2010. 118 f. Dissertação (Mestrado em Engenharia Mecânica) - Faculdade de Engenharia de llha Solteira, Universidade Estadual Paulista Júlio De Mesquita Filho, Ilha Solteira, 2010.

FERREIRA, E. S.; SILVEIRA, C. S.; LUCIEN, V. G.; AMARAL, A. S. Caracterização físico-química da amêndoa, torta e composição dos ácidos graxos majoritários do óleo bruto da castanha-do-brasil (Bertholletia excelsa H.B.K). Alimentos e Nutrição, v.17, n.2, p.203-208, abr./jun. 2006.

GONÇALVES, J. D. Equilíbrio líquido-líquido dos sistemas biodiesel de castanha do brasil + metanol + (glicerina ou água): determinação experimental e modelagem termodinâmica. 2013. 121 f. Dissertação (Mestrado em Engenharia Química) - Universidade Federal do Pará, Belém, 2013.

GRANGEIRO, R. V. T. Caracterização da água de lavagem proveniente da purificação do biodiesel. 2009. 53 f. Dissertação (Mestrado em Química) Universidade Federal da Paraíba, João Pessoa, 2009.

IAL - INSTITUTO ADOLFO LUTZ. Métodos químicos e físicos para análise de alimentos. 4ํe․ São Paulo: IAL, 2008. 1020 p. 
JUBILUT, P. R. Avaliação do Potencial de Produção de Biodiesel a partir de Gorduras Animais no Estado de Santa Catarina e Estudos de Conversão destas por Transesterificação Química. 2010. 65 f. Dissertação (Mestrado em Ciência e Tecnologia Ambiental) - Universidade do Vale do Itajaí, Itajaí, 2010.

MACHADO, S.A. Estudo da produção de biodiesel a partir do óleo de macaúba (Acrocomia aculeata) pela rota etílica. 2013. 135 f Dissertação (Mestrado em Ciências) - Escola de Engenharia de Lorena, Universidade de São Paulo, Lorena, 2013.

OLIVEIRA. N. de. ANP: consumo de combustíveis no Brasil cresceu 5\% em 2013. Agência Brasil EBC, Rio de Janeiro, 12 mar. 2014. Disponível em: <http://agenciabrasil.ebc.com.br/economia/noticia/2014-03/anp-consumo-decombustiveis-no-brasil-cresceu-5-em-2013 >. Acesso em: 04 maio 2015.

OLIVEIRA, F. I. Certificação da Castanha-do-brasil e o desenvolvimento sustentável: análise de programas de certificação e de sua aplicação em empreendimentos castanheiros amazônicos. 2011. 137 f. Dissertação (Mestrado) Universidade de Brasília, Centro de Desenvolvimento Sustentável, Brasília, 2011.

SANTOS, A. L.; KUNRATH, N. F.; SOUZA, I. S.; PANTOJA, N. V.; KISPERGHER, E. M. Obtenção e utilização de biodiesel produzido a partir de óleos residuais de fritura. In: CONGRESSO INTERNACIONAL DE BIOENERGIA, 9, 2014, São Paulo. Anais... São Paulo: Congresso Internacional de Bioenergia, 2014. 1 CD-ROM.

SILVA, T. A. R.; NETO, W. B. Estudo da Redução da Acidez do Óleo Residual para a Produção de Biodiesel Utilizando Planejamento Fatorial Fracionado. Revista Virtual de Química, v. 5, n. 5, p. 828-839, 2013. Disponível em: <http://www.uff.br/RVQ/index.php/rvq/article/download/334/333>. Acesso em: 19 mai. 2015.

SILVA, L. de L. Estudos de óleos residuais oriundos de processo de fritura e qualificação desses para obtenção de monoésteres (biodiesel). 2008. $65 \mathrm{f}$. Dissertação (Mestrado em Engenharia Química) - Unidade Acadêmica Centro de Tecnologia, Universidade Federal de Alagoas, Maceió, 2008.

SOUZA, C. D. R.; CHAAR, J. S.; SOUZA, R. C. R.; JEFFREYS, M. F.; SOUZA, K. S; COSTA, E. J. C.; SANTOS, J. C. Caracterização físico-química das misturas binárias de biodiesel e diesel comercializados no Amazonas. Acta Amazonica, v. 39(2), p. 383-388, 2009. Disponível em: <http://www.scielo.br/pdf/aa/v39n2/v39n2a17.pdf>. Acesso em: 04 set. 2015.

SOUZA, I. F. Cadeia produtiva de castanha-do-Brasil (Bertholletia excelsa) no Estado de Mato Grosso. 2006. 152 f. Dissertação (Mestrado em Agronegócios: Desenvolvimento Sustentável do Agronegócio) - Universidade Federal de Mato Grosso do Sul, Campo Grande, 2006. 